\title{
FUNCIONAMENTO DE UM SISTEMA DE CRIAÇÃO BOVINO A PARTIR DO PROCESSO DE ELABORAÇÃO DA PRODUÇÃO EM SÃO DOMINGOS DO ARAGUAIA-PA
}

\author{
Priscila Duarte Malanski' Laura Angélica Ferreira Darnet ${ }^{2}$. \\ ${ }^{1}$ Doutoranda em Zootechnie des Systèmes d'Élevage du Institut National de Recherche \\ Agronomique, Clermont-Ferrand, França.pdmalanski@ clermont.inra.fr \\ ${ }^{2}$ Profa. Dra. do Núcleo de Ciências Agrárias e Desenvolvimento Rural, Universidade Federal \\ do Pará. Belém, Pará, Brasil. laurange@ ufpa.br
}

\begin{abstract}
RESUMO: A análise do funcionamento é uma das principais ferramentas utilizadas em estudos apoiados na abordagem sistêmica e voltados para a compreensão da gestão e organização de sistemas agrícolas de produção familiar. O objetivo deste trabalho é o de proceder a uma análise do funcionamento de um sistema de criação, voltado para pecuária bovina, com ênfase no processo de elaboração da produção. Trata-se de um estudo de caso realizado em uma propriedade no Projeto de Assentamento Belo Horizonte I, em São Domingos do Araguaia-PA. Foram realizadas entrevistas entre março e dezembro de 2011. Com auxílio do software QRS-NVIVO, os dados foram categorizados para estrutura do sistema de criação e o funcionamento do sistema para o processo de elaboração da produção. Os resultados mostram que há uma classificação dos produtos pecuários enquanto produtos e subprodutos e que tal classificação direciona as práticas de manejo do agricultor. Esta classificação é estabelecida em função do objetivo produtivo estabelecido para o sistema de criação.
\end{abstract}

PALAVRAS-CHAVE: Sistema de criação. Produtos pecuários. Objetivo produtivo.

\section{FUNCTIONING OF CATTLE SYSTEM FROM PROCESS OF PREPARING THE PRODUCTION OF SÃO DOMINGOS DO ARAGUAIA-PA}

\begin{abstract}
Analysis of the functioning is a most important tool for the studies in systems approach with interest on understands family farms organization. The objective of this paper is analyze the livestock system with emphasis in elaboration process of production. It's about a case study in a farm on Settlement Belo Horizonte I, São Domingos do Araguaia-PA. Interviews were conducted between March and December 2011. With support of software QRS-NVIVO, the data were categorized for the structure of livestock systems and systems functioning for elaboration process of production. The results show that there is a classification about livestock productions as product and sub product and this classification direct the farmer's management practices. The classification is determined for the productive goal of livestock system.
\end{abstract}

KEYWORDS: Livestock system. Livestock production. Productive goal. 


\section{FUNCIONAMIENTO DE UN SISTEMA DE CRÍA DE GANADO EN EL PROCESO DE PREPARACIÓN DE LA PRODUCCIÓN EN SÃO DOMINGOS DO ARAGUAIA-PA}

RESUMEN: El análisis de la operación es una de las principales herramientas utilizadas en los estudios apoyaron el enfoque sistémico y dirigida a la comprensión de la gestión y organización de la agricultura familiar sistemas de producción. El objetivo de este estudio es realizar un análisis del funcionamiento de un sistema de cría, volvió a la ganadería, con énfasis en el desarrollo del proceso de producción. Se trata de un estudio de caso realizado en una propiedad en la solución de proyecto I Belo Horizonte, São Domingos do Araguaia-PA. Las entrevistas entre marzo y diciembre de 2011.-Con la ayuda de un software QRS NVivo, los datos se clasificaron para estructurar el sistema de construcción y el sistema operativo para el proceso de elaboración de la producción se realizaron. Los resultados muestran que existe una clasificación de los productos animales y subproductos rato y que dicha clasificación dirige las prácticas de manejo del agricultor. Esta clasificación se determina sobre la base de la meta de producción establecida para el sistema de creación.

PALABRAS-CLAVE: Cría. Productos pecuarios. Sistema de metas de producción.

\section{INTRODUÇÃO}

A forma como o agricultor articula a estrutura e os fluxos de seu sistema de criação bovino tem a finalidade de organizar o processo de elaboração da produção para obter $\mathrm{o}(\mathrm{s})$ produto(s) pecuário(s). A elaboração da produção é um processo complexo que envolve fatores relacionados tanto ao animal quanto ao homem.

Segundo Osty e Landais (1991), compete aos animais produzir o(s) produto(s) e compete ao homem analisar as condições restritivas e favoráveis do contexto socioeconômico para traçar seus objetivos e, então, processar suas decisões de como executar suas ações no tempo e no espaço (suas práticas). Logo, é a articulação e complementaridade entre estas respectivas competências que estruturam o processo de elaboração da produção no sistema de criação.

Para Dedieu et al. (2008), as práticas ocupam o lugar de interface entre as competências do homem e do animal, uma vez que é através das práticas do homem que as condições para o animal produzir são modificadas.

Se por um lado, segundo Landais (1987), as práticas são uma importante "porta de entrada" para compreender o funcionamento do sistema de criação e como tal deve contribuir na identificação do objetivo que guia este funcionamento. Por outro, para Bourgeios (1983), os fluxos também se tornam importantes para compreender como as relações entre os 
elementos do sistema de criação se estabelecem e organizam o funcionamento do próprio sistema.

É o agricultor, acompanhado ou não de um ou mais membros da família, enquanto gestor do sistema de criação, quem atribui os objetivos, os usos e as funções para as atividades que desenvolve, seguindo critérios de escolhas que lhes são próprios (BOURGEOIS, 1983). Para Osty e Landais (1991), em sistemas de criação, estes critérios se baseiam em objetivos estabelecidos e almejados pelo agricultor e sua família em relação ao produto animal que se quer produzir.

$\mathrm{Na}$ Amazônia Oriental, os sistemas de criação familiar caracterizam-se pela não especialização da produção pecuária, mas pela opção dos agricultores familiares pela dupla finalidade produtiva do rebanho, leite e bezerros (POCCARD-CHAPUIS et al., 2003).

Contudo, neste artigo, parte-se da hipótese de que mesmo em sistemas de criação de dupla finalidade produtiva, existe uma classificação hierárquica entre os produtos pecuários (leite e bezerro) que define o objetivo produtivo do processo de elaboração da produção e influencia o funcionamento do sistema de criação. A partir de um estudo de caso de um sistema de criação de dupla finalidade produtiva, tem-se como objetivo identificar a existência (ou inexistência) da classificação hierárquica entre os produtos pecuários e analisar sua influencia sobre o processo de elaboração da produção.

\section{MATERIAL E MÉTODOS}

Trata-se de um estudo de caso realizado no estabelecimento agrícola do agricultor A, localizado no Projeto de Assentamento Belo Horizonte I, em São Domingos do Araguaia (Sudeste do Pará).

$\mathrm{O}$ agricultor tem três lotes, os quais juntos somam 170 ha. A pastagem ocupa 111 ha divididos em 6 piquetes de tamanhos que variam entre 5 e 20 ha.

O rebanho é formado por 117 cabeças (Tabela 1) divididas entre dois lotes. As matrizes e três reprodutores são mestiços, provenientes de vários cruzamentos entre nelore x gir, e nelore x holandês. Apenas um reprodutor é da raça nelore.

O rebanho pasta em piquetes diferentes de forma rotacionada, sendo: 3 piquetes para o lote 1 ; e 3 piquetes para o lote 2.

As gramíneas que formam o pasto são o mombaça (Panicum maximum cv. Mombaça), braquiarão (Brachiaria brizantha cv. Marandu), braquiária d'água (Brachiaria radicans) e gramão (Cynodon dactylon). 
Tabela 1 - Estrutura do rebanho no ano de 2011.

\begin{tabular}{lc}
\hline Categoria Animal & Quantidade (cabeças) \\
\hline Matrizes & 48 \\
Reprodutor & 4 \\
Novilhas & 40 \\
Novilhos & 15 \\
Bezerros & 18 \\
Bezerras & 12 \\
Total rebanho & 117 \\
\hline
\end{tabular}

FONTE: pesquisa de campo.

Entre março e dezembro de 2011 foram coletados dados sobre: 1) Família: número de membros que moram no estabelecimento agrícola, utilização da mão-de-obra familiar, atividade realizada por cada membro da família; 2) rebanho bovino: quantidade, raça, divisão em lotes; 3) pastagem: tamanho, número de piquetes, espécies forrageiras; 4) Comercialização de produtos: quais produtos, tipo de comprador (atravessador ou venda direta ao cliente).

Tais dados foram coletados por meio de observação não participante, conversas informais e um questionário aberto. Utilizou-se o software QRS-NVIVO para: 1) compilação dos dados; e 2) para identificar categorias de análise (em destaque) de acordo com as orientações metodológicas de:

a) Osty e Landais (1991) sobre o processo de elaboração da produção cujas etapas são: i) Objetivo produtivo: objetivo de produção relacionado ao produto animal que guia o processo de elaboração da produção; ii) As decisões tomadas pelo agricultor e sua família; iii) Práticas: manejo do rebanho e da pastagem; iv) Elaboração da produção: processos biológicos próprios aos animais que são influenciados pelos recursos oferecidos, como forragem, água, suplementos, e pelas práticas de manejo adotadas pelo agricultor; v) Produtos: produtos pecuários resultantes do processo de elaboração da produção.

b) Lhoste (1999) sobre a estrutura do sistema de criação, i) rebanho: quantidade, divisão em lotes e raça; ii) pastagem: tamanho, quantidade de piquetes e espécies forrageiras

c) Bourgeois (1983) sobre funcionamento do sistema: fluxos que compreendem i) os destinos dos produtos; ii) investimento da renda obtida com a venda dos produtos pecuários; e iii) a distribuição de mão de obra nas práticas de manejo. 


\section{RESULTADOS E DISCUSSÃO}

Graças à característica mestiça do rebanho, o agricultor pode explorar a produção de leite e de bezerros. Contudo, de acordo com o mesmo, os cruzamentos entre nelore $\mathrm{x}$ gir e nelore $\mathrm{x}$ holandês não são favoráveis quando se quer produzir leite, por outro lado, podem compensar pela venda do bezerro.

Segundo Carvalho, Tourrand e Poccard-Chapuis (2012), a produção de leite e bezerro, ou também chamada "dupla finalidade produtiva", é uma situação considerada comum entre as propriedades familiares na região da Transamazônica. Poccard-Chapuis et al. (2003) apontam que dessa maneira o agricultor pode se favorecer de uma certa regularidade na produção e na renda proveniente do leite e contar com a produção e renda pontual dos bezerros.

O rebanho é divido em dois lotes. Lote 1 é composto por reprodutor mestiço, matrizes lactantes e bezerros até seis meses. O lote 2 é composto pelo reprodutor nelore, novilhos, matrizes em período de serviço e bezerros apartados (a partir do sétimo mês). Apesar da dupla finalidade produtiva, observa-se que o produto de cada lote é específico: lote 1 leite; lote 2 - bezerros e novilhos.

Segundo Landais (1987), ao analisarmos a prática de divisão do rebanho em lotes associada à escolha do nelore como raça principal para cruzamentos mistos e como raça de um dos seus reprodutores, pode-se indicar que existe uma tendência do agricultor para a produção com maior foco aos bezerros do que na produção de leite.

$\mathrm{O}$ agricultor vende bezerros e novilhos para fazendeiros vizinhos ao assentamento ou revendedores da região. Para Veiga, Poccard-chapuis e Tourrand (2003) esta prática comercial entre agricultores e fazendeiros permite uma certa verticalização da produção e coloca o agricultor familiar em contato com a cadeia produtiva. A renda obtida com venda é distribuída entre: 1) a família com a manutenção da casa e gastos pessoais; 2) o rebanho - sal mineral e vacinas; 3) a pastagem - construção de cercas, reformas e contratação de diárias; 4) em casos emergenciais. Carvalho, Tourrand e Poccard-Chapuis (2012) encontraram dinâmica de investimento da renda similar em propriedades familiares de dupla finalidade produtiva em Brasil Novo (Sudoeste do Pará).

Contudo, no caso do agricultor nesse estudo, a principal fonte de renda é proveniente do cacau ${ }^{1}$ (Theobroma cacao

\footnotetext{
${ }^{1}$ O fluxo monetário oriundo tanto do sistema de criação como no de cultivo retorna aos próprios sistemas na forma de trabalho e de materiais para a manutenção. Todavia a família capta parte do fluxo
} 
L.) (6 ha), em decorrência da importância relativa entre as rendas, o sistema de criação assume caráter complementar ao sistema de cultivo. De acordo com Bourgeios (1983), pode-se interpretar que é a relação de complementaridade entre os sistemas de cultivo e de criação que organiza o funcionamento do sistema de produção do agricultor.

Somente o agricultor (60 anos) e sua esposa (52 anos) vivem no lote e trabalham no cacaueiro. Seus dois filhos constituíram família e também moram no assentamento. Um deles é o responsável pelo manejo da pastagem, do rebanho e ordenha diária das matrizes. Por este trabalho, o agricultor A repassa o leite produzido como forma de pagamento. Mesmo o filho fazendo as práticas de manejo, quem decide o que e quando fazer ainda é o agricultor $\mathrm{A}$.

Esse arranjo funcional do sistema de criação, em que o agricultor toma as decisões e o filho executa as práticas de manejo, torna-se viável em função da 1) importância econômica do sistema de cultivo, que oferece a possibilidade do agricultor A lançar mão da renda do leite para contratar força de trabalho do filho, e 2) do interesse prioritário do agricultor $A$ em vender o bezerro.
Para Osty e Landais (1991), tais condições revelam os critérios escolhidos pelo agricultor para definir seu objetivo produtivo e organizar o processo de elaboração da produção. Para o caso em análise, o processo de elaboração da produção é organizado em função de se obter como produto principal o bezerro. $\mathrm{O}$ leite caracteriza-se como subproduto neste processo (Figura 1).

\section{CONCLUSÕES}

Considerando sistemas de criação familiar que não têm uma especialização produtiva definida, mas valem-se da dupla finalidade produtiva, é comum classificarmos o resultado da produção bovina enquanto produtos pecuários sem que haja uma diferenciação entre eles, sugerindo que os sistemas de criação de dupla finalidade constituem um universo de produção homogêneo.

A análise do funcionamento do sistema de criação do agricultor A com foco no processo de elaboração da produção mostrou que, diferente disso, existe uma classificação hierárquica entre produto e subproduto e sugere que aquela homogeneidade é apenas aparente.

Isso nos leva a crer que, apesar dos sistemas de criação bovino apresentarem

monetário para suprir as necessidades de consumo dos seus membros. semelhanças quanto aos produtos pecuários (leite e bezerro), cada um destes 
sistemas pode apresentar objetivos produtivos diferentes, seja ele voltado para a produção de leite, de bezerros ou ambos. Esta diferenciação torna-se importante porque no processo de elaboração da produção é o interesse prioritário do agricultor em relação ao produto que orienta o funcionamento do sistema de criação.

Como trata-se de um estudo de caso, é necessário replicar o estudo em outras amostras para abranger uma diversidade de situações e propor generalizações contundentes. Contudo, ressalta-se que, mesmo em nível exploratório a hipótese lançada mostrou-se pertinente. Além disso, o resultado obtido tem grande relevância para a agricultura familiar porque fornece pistas sobre como os agricultores organizam sua produção. Este tipo de informação é importante especialmente para assistência técnica. O prestador de assistência técnica não pode aconselhar a mesma condução técnica para sistemas de criação de dupla finalidade produtiva com objetivos produtivos diferentes.

Figura 1 - Modelização do sistema de criação do agricultor.

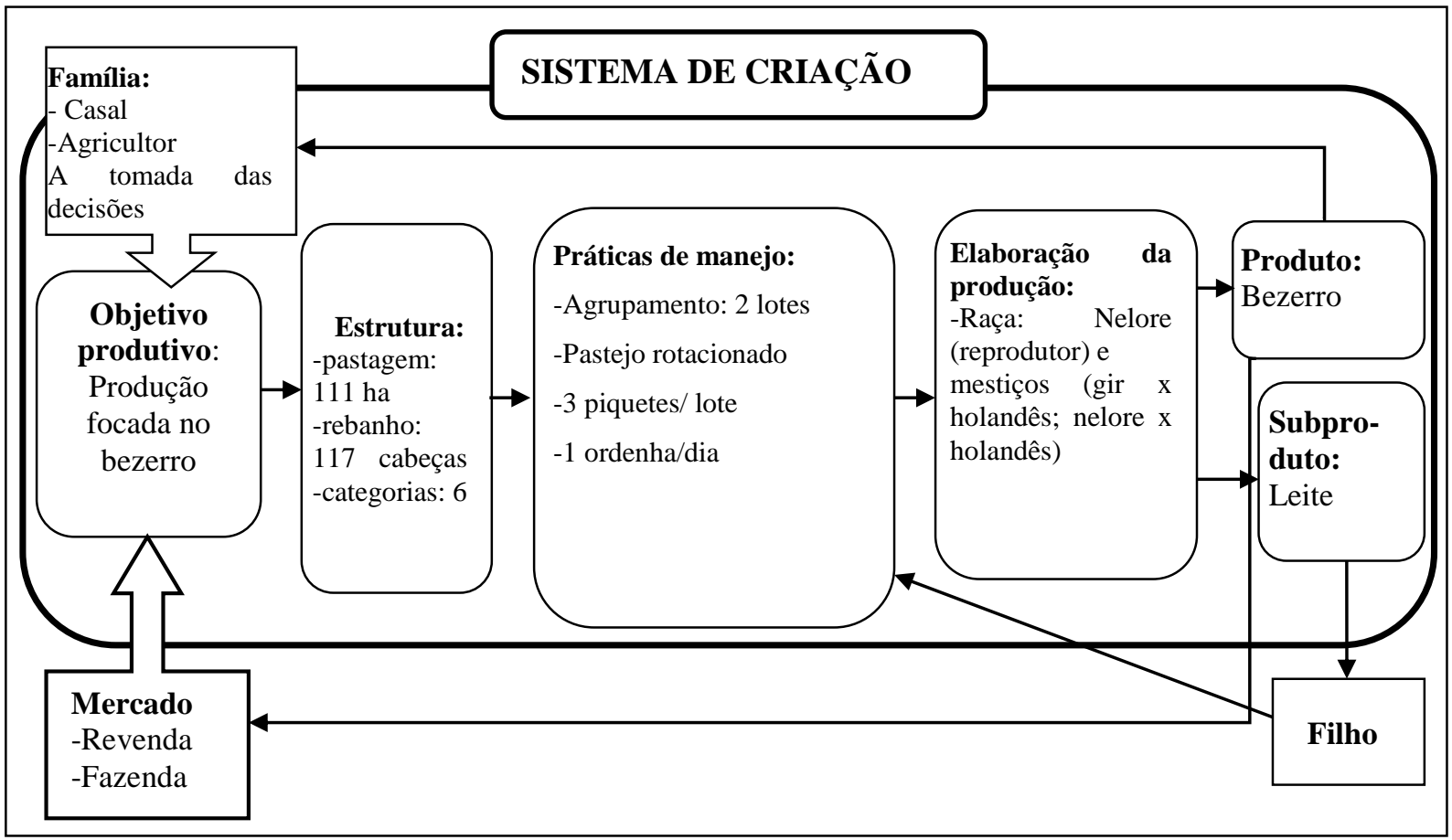

FONTE: Elaborado pelas autoras.

\section{AGRADECIMENTOS}

Ao Conselho Nacional de Desenvolvimento Científico e Tecnológico
(CNPq) pelo apoio financeiro ao projeto de pesquisa e extensão Promover Inovações para o Fortalecimento da Agricultura 
Familiar em Assentamentos do Sudeste do

Pará.

\section{REFERÊNCIAS}

BOURGEOIS, A. Une Application de la notion de système: l'exploitation agricole. Agriscope, v.1, n. 1, p. 15-31, 1983.

CARVALHO, S. A. de; TOURRAND, J-F; POCCARD-CHAPUIS, R. Atividade leiteira: um desafio para a consolidação da agricultura familiar na região da Transamazônica, no Pará. Cadernos de Ciência \& Tecnologia, Brasília, v. 29, n. 1, p. 269-290, jan./abr. 2012

DEDIEU, B.; FAVERDIN, P.; DOURMAD, J. Y.; GIBON, A. Système d'élevage, un concept pour raisonner les transformations de l'élevage. INRA production animal, v. 21. n. 1, 2008.

LANDAIS, E. Pesquisas sobre sistemas de criação: questões e perspectivas. Tradução de Lívia Navegantes-Alves e Letícia de Freitas Navegantes. Montpellier: INRA, 1987.

LHOSTE, P. Os Sistemas de criação em zona tropical: conceitos e métodos de estudos. Tradução de Laura Angélica Ferreira. Belém: UFPA, 1999.

OSTY, P. L.; LANDAIS, E. Fonctionnement des systèmes d'exploitation pastorale. CONGRÈS INTERNATIONAL DES TERRES DE PARCOURS, 1991, Montpellier. Actes... Montpellier, França: IRD, 1991.

POCCARD-CHAPUIS, R., et al. A cadeia produtiva do leite: Uma alternativa para consolidar a agricultura familiar nas frentes pioneiras da Amazônia? In: TOURRAND, J. F.; VEIGA, J. B. Viabilidade de sistemas agropecuários na agricultura familiar da
Amazônia. Belém: Embrapa Amazônia Oriental, 2003. p. 355-372.

VEIGA, J. B.; POCCARD-CHAPUIS, R.; TOURRAND, J-F. Caracterização e viabilidade agropecuária na agricultura familiar da Amazônia Oriental brasileira. In: TOURRAND, J.-F.; VEIGA, J. B. Viabilidade de sistemas agropecuários na agricultura familiar da Amazônia. Belém: EMBRAPA Amazônia Oriental, (2003). 